\title{
Antibiotic susceptibility of Lactobacillus rhamnosus strains isolated from Parmigiano Reggiano cheese
}

\author{
Raffaele COPPOLA ${ }^{\text {a* }}$, Mariantonietta SUCCI ${ }^{\mathrm{a}}$, Patrizio TREMONTEa ${ }^{\mathrm{a}}$, \\ Anna REALE ${ }^{\mathrm{a}}$, Giovanni SALZANO ${ }^{\mathrm{b}}$, Elena SORRENTINO ${ }^{\mathrm{a}}$ \\ a Dipartimento di Scienze e Tecnologie Agro-alimentari, Ambientali e Microbiologiche, \\ Università degli Studi del Molise, Campobasso, Italy \\ ${ }^{\text {b }}$ Dipartimento di Biologia e Difesa Agro-forestale, Università degli Studi della Basilicata, Potenza, Italy
}

Received 24 May 2004 - Accepted 24 January 2005

Published online 26 April 2005

\begin{abstract}
This work aimed to evaluate the antibiotic susceptibility of 63 Lactobacillus rhamnosus strains isolated from Parmigiano Reggiano cheese, of Lactobacillus GG and of the type strain L. rhamnosus DSM 20021. Antimicrobial susceptibility was determined by the disc diffusion method on 41 antibiotics. Inhibition zone diameter was carefully measured and the results (the mean of four determinations) were expressed in terms of resistance or susceptibility. All the strains isolated from cheese showed resistance to six antibiotics (cefixime, vancomycin, neomycin, enoxacin, pefloxacin and sulphamethoxazole plus trimethoprim). The strain DSM $20021^{\mathrm{T}}$ was resistant to nine antibiotics (the previous six plus cephalexin, bacitracin and lincomycin), while the commercial strain $L$. GG showed resistance to eighteen antibiotics. A high strain-specific resistance to different antibiotics was ascertained in Lactobacillus rhamnosus isolated from cheese. The results obtained in this study confirm that antibiotic resistance is a very important feature in the selection of potentially probiotic lactic acid bacteria.
\end{abstract}

Lactobacillus rhamnosus / lactic acid bacteria / antibiotic susceptibility / cheese / probiotic

Résumé - Sensibilité aux antibiotiques de souches de Lactobacillus rhamnosus isolées du fromage Parmigiano Reggiano. Le but de cette étude était l'évaluation de la sensibilité aux antibiotiques de 63 souches de Lactobacillus rhamnosus isolées du fromage Parmigiano Reggiano, de la souche Lactobacillus GG et de la souche type de L. rhamnosus DSM 20021. La sensibilité ou la résistance à 41 antibiotiques de ces 65 souches de L. rhamnosus a été déterminée avec le test de diffusion de disque en gélose. Les diamètres des zones d'inhibition, mesurés avec précision, ont permis d'individualiser pour chaque antibiotique testé les souches résistantes et celles sensibles. Toutes les souches isolées du fromage se sont avérées résistantes à six antibiotiques (céfixime, vancomycine, néomycine, enoxacine, péfloxacine et triméthoprime + sulfaméthoxazole). La souche type DSM $20021^{\mathrm{T}}$ était résistante à neuf antibiotiques (les six précédents plus cefalexine, bacitracine et lincomycine), tandis que la souche commerciale $L$. GG a montré une résistance à 18 antibiotiques. Une résistance souche-spécifique à différents antibiotiques a été montrée pour les souches de Lactobacillus rhamnosus isolées du fromage. Les résultats obtenus dans cette étude ont confirmé que la résistance aux antibiotiques est une caractéristique très importante pour sélectionner les bactéries lactiques potentiellement probiotiques.

Lactobacillus rhamnosus / bactérie lactique / sensibilité aux antibiotiques / fromage / probiotique

\footnotetext{
* Corresponding author: coppola@unimol.it
} 


\section{INTRODUCTION}

Lactobacillus species are considered as part of the normal microflora of the gastrointestinal and female genital tract [6], and also as major components of microflora involved in food fermentation [38].

Probiotic products that contain lactobacilli have long histories of safe use [10].

Bacteriosis caused by lactobacilli is considered to be rare but risk factors related to Lactobacillus species include impaired host defences and severe underlying diseases, as well as prior surgery and prolonged antibiotic therapy ineffective for lactobacilli [36].

However, widespread use of antibiotics could be responsible for significant changes in the composition of human microflora and for the rise of new pathogenic bacterial strains.

The most frequent clinical side effect of antibiotics is diarrhoea, with greater risks when they are prescribed for general purposes and taken orally [9].

Amongst the groups of patients most susceptible to these side effects are the elderly [26], the undernourished, and those who have either undergone surgery or who have been hospitalised for long periods.

Antibiotic susceptibility of probiotic microorganisms is a fundamental requisite due to the possibility that an antibiotic-resistant strain may not be easily eliminated in the case of negative influence on the host [1, $18]$ and that antibiotic resistance could be subsequently transmitted to pathogenic or potentially pathogenic micro-organisms.

The data on drug resistance of the industrially important lactobacilli are rare but some species of lactic acid bacteria that are commonly used in the food industry, or naturally found in food raw material, are well known as intrinsically resistant to some antibiotics, e.g., vancomycin [42]. However, these bacteria are susceptible to many other antibiotics and they have not been reported to easily acquire antibiotic resistance determinants like the enterococci [11].
Within the context of a large-scale research project aimed at isolating and characterising lactic acid bacteria in food, this study examined the antibiotic resistance of Lactobacillus rhamnosus strains of potentially probiotic interest isolated from Parmigiano Reggiano cheese, a hard cooked Italian cheese produced with partly skimmed raw cow milk to which natural whey starter is added and which is then ripened for 12 24 months [15, 16, 32].

Parmigiano Reggiano cheese plays the leading role in the Italian dairy industry and could represent an optimal source of potentially probiotic bacteria thanks to the presence of high amounts of viable micro-organisms at the end of the ripening (up to 24 months), i.e., at the moment of consumption.

This aspect is not negligible, considering that recent studies showed low viability of probiotics in the market preparations [25].

The reason for focusing on Lactobacillus rhamnosus strains is tied to many studies, in which the positive effects of the attachment of this particular micro-organism to human intestinal mucosa are reported [3, $19,30,31,35,37]$.

\section{MATERIALS AND METHODS}

\subsection{Bacterial strains}

A total of 63 strains of Lactobacillus rhamnosus, isolated from different samples of Parmigiano Reggiano cheese (from 4 different dairy plants located in various areas of production) at the end of the ripening (24 months) [15, 16, 32], were used in the present study (Tab. I).

The strains had been phenotypically identified according to Hammes and Vogel [21] and by API $50 \mathrm{CH}$ (Biomerieux, Marcy l'Étoile, France) according to Nigatu [34] (data not shown).

L. rhamnosus GG was isolated from a pharmaceutical preparation (Valio LTD, Helsinki, Finland) and revitalised in MRS broth (Oxoid, Milano, Italy) at $37{ }^{\circ} \mathrm{C}$. 
Table I. Provenience of L. rhamnosus strains isolated from Parmigiano Reggiano cheese at the end of the ripening.

\begin{tabular}{lccccc}
\hline & \multicolumn{5}{c}{ Dairy plants } \\
& A & B & E & G \\
\hline Number of cheese samples & 3 & 3 & 3 & 3 \\
Number of isolates at $45^{\circ} \mathrm{C}$ & 21 & 10 & 11 & 21 \\
Identified as L. rhamnosus & 21 & 10 & 11 & 21 \\
Last isolation dilution & -4 & -3 & -4 & -4 \\
\hline
\end{tabular}

L. rhamnosus type strain DSM 20021 was provided by the Deutsche Sammlung von Mikroorganismen und Zellkulturen $\mathrm{GmbH}$ (Braunschweig, Germany) and revitalised in MRS broth (Oxoid, Milano, Italy) at $37{ }^{\circ} \mathrm{C}$ according to the prescription of DSMZ.

RAPD-PCR analysis [4] was performed with the aim of differentiating the strains of Lactobacillus rhamnosus assayed (63 strains from Parmigiano Reggiano cheese plus $L$. GG) using as a reference $L$. rhamnosus DSM $20021^{\mathrm{T}}$.

PCR reaction was performed in a Mastercycler gradient (Eppendorf, Hamburg, Germany), using the primers M13 [24] and D8635 [2].

Amplification products were separated by electrophoresis on $1.5 \%$ (w/v) agarose gel in $0.5 \times$ TBE buffer. RAPD-PCR profiles were obtained directly using the digital camera ImageMaster VDS (Amersham Pharmacia Biotech, Milano, Italy) and analysed with the pattern analysis software package, Gel Compar Version 4.1 (Applied Maths, Kortrijk, Belgium).

Calculation of similarities in the profiles of bands was based on the Pearson productmoment correlation coefficient. A dendrogram was obtained by means of the Unweighted Pair Group Method using the Arithmetic Average (UPGMA) clustering algorithm [44].

\subsection{Lactobacillus rhamnosus species-specific PCR}

The specific PCR was performed on 17 strains previously identified by RAPDPCR as L. rhamnosus and belonging to different clusters and on 8 strains of $L$. paracasei subsp. paracasei from the DISTAAM collection (University of Molise), isolated from different cheeses. The conditions for specificity testing were the same as those reported for RAPD-PCR.

For comparative purposes the following type strains were used: L. casei DSM $20011^{\mathrm{T}}$, L. paracasei $\mathrm{subsp}$. paracasei DSM $5622^{\mathrm{T}}$, and L. rhamnosus DSM $20021^{\mathrm{T}}$.

PCR reaction was performed in a Mastercycler gradient (Eppendorf, Hamburg, Germany), using the following primers:

Y2: 5' CCCACTGCTGCCTCCCGTAGGAGT 3' [45];

rhamn: 5' TGCATCTTGATTTAATTTTG 3' [45].

The amplification profile was an initial step of $94{ }^{\circ} \mathrm{C}$ for $3 \mathrm{~min}$, and then 30 cycles of: $94{ }^{\circ} \mathrm{C}$ for $45 \mathrm{sec}, 55^{\circ} \mathrm{C}$ for $45 \mathrm{sec}$, and $72{ }^{\circ} \mathrm{C}$ for $1 \mathrm{~min}$.

Amplification products were separated by electrophoresis on $1.5 \%(\mathrm{w} / \mathrm{v})$ agarose gel in $0.5 \times$ TBE buffer.

\subsection{Antimicrobials}

The susceptibility of L. rhamnosus strains was determined against 41 antibiotics. Antimicrobial susceptibility discs were obtained from Oxoid (Milano, Italy). The discs were stored in sealed containers with a desiccant at $4{ }^{\circ} \mathrm{C}$. The antibiotics used for this study were cell wall synthesis, protein synthesis or nucleic acid synthesis inhibitors. Antibiotics were selected according to the experiment of Charteris et al. [14], and also by considering antibiotic treatments in standard use in hospitals.

\subsection{Antimicrobial susceptibility test}

Antibiotic susceptibility was semi-quantitatively determined by disc diffusion on 
MRS agar using a modification of the National Committee for Clinical Laboratory Standards [33] as described by Charteris et al. [14]. Inhibition zone diameter was carefully measured after anaerobic incubation at $37^{\circ} \mathrm{C}$ for $24 \mathrm{~h}$ (Anaerogen, Oxoid) using sliding callipers and the results (the mean of four determinations) were expressed in terms of resistance $(\mathrm{R})$, moderate susceptibility (MS) or susceptibility (S) [7].

The statistical program Systat Version 11 (Systat Software, Inc., Richmond, USA) was utilised to calculate the similarity in the antibiotic-susceptibility profiles of the 65 strains. A dendrogram was obtained using the same parameters utilised in the RAPD-PCR analysis (average linkage and Pearson correlation) for comparative purposes.

\section{RESULTS}

\subsection{Susceptibility to inhibitors of cell wall synthesis}

Among penicillins (Tab. II), ampicillin, cloxacillin, mezlocillin, piperacillin and ticarcillin showed a strong inhibitory activity on all the strains tested; penicillin $\mathrm{G}$ inhibited $95 \%$ of the strains, while the remaining $5 \%$ were moderately susceptible to this antibiotic. L. rhamnosus DSM $20021^{\mathrm{T}}$ and L. GG were sensible to the previous antibiotics.

Resistance was shown by $71 \%$ and $68 \%$ of strains isolated from Parmigiano Reggiano cheese to amoxicillin and oxacillin, respectively; L. rhamnosus DSM $20021^{\mathrm{T}}$ and $L$. GG showed a moderate sensibility or resistance to these antibiotics, respectively.

Among cephalosporins, it was possible to note a strain-specific response to this class of antibiotics. In particular, a high percentage of L. rhamnosus strains showed resistance to cefadroxil, cephalexin and ceftriaxone, while a high percentage showed susceptibility to cefazolin, cefoperazone and cefuroxime. All the strains tested were resistant to cefixime, while $24 \%, 43 \%$ and $33 \%$ of them were, respectively, sensible, moderately sensible or resistant to ceftazidime. L. GG was sensible to cefazolin, moderately sensible to cefoperazone and resistant to all the other cephalosporins. DSM $20021^{\mathrm{T}}$ showed sensibility to cefazolin, cefoperazone, ceftazidime and cefuroxime, moderate sensibility to cefadroxil and ceftriaxone and resistance to cephalexin and cefixime.

Assays for beta-lactamase inhibitors revealed susceptibility of all the strains to amoxicillin-clavulanic acid, ampicillin-sulbactam and piperacillin-tazobactam, while $76 \%, 10 \%$ and $14 \%$ of the assayed strains were sensible, moderately sensible or resistant to ticarcillin-clavulanic acid, respectively. DSM $20021^{\mathrm{T}}$ showed sensibility to all $\beta$-lactamase inhibitors tested, while $L$. GG was resistant to ticarcillin-clavulanic acid.

Among the other single inhibitors of cell wall synthesis, all strains were susceptible to imipenem and resistant to vancomycin but a high resistance to bacitracin and teicoplanin was also evidenced by $73 \%$ and $95 \%$ of assayed strains, respectively. L. rhamnosus DSM $20021^{\mathrm{T}}$ was susceptible to imipenem, moderately sensible to teicoplanin and resistant to bacitracin and vancomicyn, while $L$. GG showed sensibility to imipenem only.

\subsection{Susceptibility to protein synthesis inhibitors}

All strains showed susceptibility to tetracyclines (tetracycline, minocycline and doxicycline), to chloramphenicol and, among macrolides, to erythromycin, josamycin and spiramycin, while $93 \%, 5 \%$ and $2 \%$ were sensible, moderately sensible or resistant to clarithromycin, respectively.

Among lincosamides, clindamycin showed inhibitory effects against all the tested strains, while $14 \%$ and $86 \%$ of the strains were susceptible or resistant to lincomycin, respectively.

Almost all the strains were resistant to aminoglycosides (gentamicin and neomicyn). In fact, only $2 \%$ showed susceptibility to gentamicin. L. rhamnosus DSM $20021^{\mathrm{T}}$ 
Table II. Susceptibility to 41 antibiotics of L. rhamnosus (63 strains) isolated from Parmigiano Reggiano cheese, of L. rhamnosus DSM $20021^{\mathrm{T}}$ and $L$. GG (\% of susceptible, moderately susceptible or resistant strains).

\begin{tabular}{|c|c|c|c|c|c|c|c|}
\hline \multirow{2}{*}{$\begin{array}{l}\text { Group } \\
\text { Inhibitors of cell wall synthesis }\end{array}$} & \multirow[t]{3}{*}{ Name } & \multirow[t]{3}{*}{ Potency } & \multicolumn{5}{|c|}{ Antimicrobial susceptibility ${ }^{a}$} \\
\hline & & & \multirow{3}{*}{$\frac{S}{2}$} & \multirow{3}{*}{$\frac{\text { MS }}{27}$} & \multicolumn{3}{|c|}{ DSM } \\
\hline & & & & & $\mathrm{R}$ & $20021^{\mathrm{T}}$ & L. GG \\
\hline \multirow[t]{8}{*}{ Penicillins } & Amoxicyllin & $10 \mu \mathrm{g}$ & & & 71 & MS & $\mathrm{R}$ \\
\hline & Ampicillin & $10 \mu \mathrm{g}$ & 100 & 0 & 0 & S & $\mathrm{S}$ \\
\hline & Cloxacillin & $5 \mu \mathrm{g}$ & 100 & 0 & 0 & S & $S$ \\
\hline & Mezlocillin & $75 \mu \mathrm{g}$ & 100 & 0 & 0 & S & $S$ \\
\hline & Oxacillin & $1 \mu \mathrm{g}$ & 5 & 27 & 68 & MS & $\mathrm{R}$ \\
\hline & Penicillin G & 10 I.U.* & 95 & 5 & 0 & $\mathrm{~S}$ & $\mathrm{~S}$ \\
\hline & Piperacillin & $100 \mu \mathrm{g}$ & 100 & 0 & 0 & S & $S$ \\
\hline & Ticarcillin & $75 \mu \mathrm{g}$ & 100 & 0 & 0 & S & $S$ \\
\hline \multirow[t]{8}{*}{ Cephalosporins } & Cefadroxil & $30 \mu \mathrm{g}$ & 8 & 19 & 73 & MS & $\mathrm{R}$ \\
\hline & Cephalexin & $30 \mu \mathrm{g}$ & 5 & 0 & 95 & $\mathrm{R}$ & $\mathrm{R}$ \\
\hline & Cefazolin & $30 \mu \mathrm{g}$ & 67 & 24 & 9 & $\mathrm{~S}$ & $\mathrm{~S}$ \\
\hline & Cefixime & $5 \mu \mathrm{g}$ & 0 & 0 & 100 & $\mathrm{R}$ & $\mathrm{R}$ \\
\hline & Cefoperazone & $75 \mu \mathrm{g}$ & 86 & 11 & 3 & $\mathrm{~S}$ & MS \\
\hline & Ceftazidime & $30 \mu \mathrm{g}$ & 24 & 43 & 33 & $\mathrm{~S}$ & $\mathrm{R}$ \\
\hline & Ceftriaxone & $30 \mu \mathrm{g}$ & 2 & 46 & 52 & MS & $\mathrm{R}$ \\
\hline & Cefuroxime & $30 \mu \mathrm{g}$ & 71 & 5 & 24 & $\mathrm{~S}$ & $\mathrm{R}$ \\
\hline \multirow[t]{4}{*}{$\beta$-lactamase inhibitors } & Amoxicillin-clavulanic acid & $30 \mu \mathrm{g}$ & 100 & 0 & 0 & S & $\mathrm{S}$ \\
\hline & Ampicillin-sulbactam & $20 \mu \mathrm{g}$ & 100 & 0 & 0 & $\mathrm{~S}$ & $S$ \\
\hline & Piperacillin-tazobactam & $110 \mu \mathrm{g}$ & 100 & 0 & 0 & S & S \\
\hline & Ticarcillin-clavulanic acid & $85 \mu \mathrm{g}$ & 76 & 10 & 14 & $\mathrm{~S}$ & $\mathrm{R}$ \\
\hline \multirow[t]{4}{*}{ Single antibiotics } & Imipenem & $10 \mu \mathrm{g}$ & 100 & 0 & 0 & $\mathrm{~S}$ & $\mathrm{~S}$ \\
\hline & Bacitracin & 10 I.U.* & 24 & 3 & 73 & $\mathrm{R}$ & $\mathrm{R}$ \\
\hline & Teicoplanin & $30 \mu \mathrm{g}$ & 2 & 3 & 95 & MS & $\mathrm{R}$ \\
\hline & Vancomycin & $30 \mu \mathrm{g}$ & 0 & 0 & 100 & $\mathrm{R}$ & $\mathrm{R}$ \\
\hline \multicolumn{8}{|l|}{ Inhibitors of protein synthesis } \\
\hline \multirow[t]{3}{*}{ Tetracyclines } & Doxicycline & $30 \mu \mathrm{g}$ & 100 & 0 & 0 & $\mathrm{~S}$ & $\mathrm{~S}$ \\
\hline & Minocyclin & $30 \mu \mathrm{g}$ & 100 & 0 & 0 & $\mathrm{~S}$ & $\mathrm{~S}$ \\
\hline & Tetracyclin & $30 \mu \mathrm{g}$ & 100 & 0 & 0 & $\mathrm{~S}$ & $S$ \\
\hline \multirow[t]{2}{*}{ Aminoglycosides } & Gentamicin & $10 \mu \mathrm{g}$ & 2 & 0 & 98 & $\mathrm{~S}$ & $\mathrm{R}$ \\
\hline & Neomycin & $30 \mu \mathrm{g}$ & 0 & 0 & 100 & $\mathrm{R}$ & $\mathrm{R}$ \\
\hline \multirow[t]{4}{*}{ Macrolides } & Clarithromycin & $15 \mu \mathrm{g}$ & 93 & 5 & 2 & $\mathrm{~S}$ & MS \\
\hline & Erythromycin & $15 \mu \mathrm{g}$ & 100 & 0 & 0 & $\mathrm{~S}$ & $\mathrm{~S}$ \\
\hline & Josamycin & $30 \mu \mathrm{g}$ & 100 & 0 & 0 & $\mathrm{~S}$ & $S$ \\
\hline & Spiramycin & $100 \mu \mathrm{g}$ & 100 & 0 & 0 & $\mathrm{~S}$ & $S$ \\
\hline \multirow[t]{2}{*}{ Lincosamides } & Clindamycin & $2 \mu \mathrm{g}$ & 100 & 0 & 0 & $\mathrm{~S}$ & S \\
\hline & Lincomycin & $2 \mu \mathrm{g}$ & 14 & 0 & 86 & $\mathrm{R}$ & $\mathrm{R}$ \\
\hline Single antibiotics & Chloramphenicol & $30 \mu \mathrm{g}$ & 100 & 0 & 0 & $\mathrm{~S}$ & $\mathrm{~S}$ \\
\hline \multicolumn{8}{|l|}{ Inhibitors of nucleic acid synthesis } \\
\hline Rifamicins & Rifampicin & $5 \mu \mathrm{g}$ & 100 & 0 & 0 & $\mathrm{~S}$ & $\mathrm{~S}$ \\
\hline \multirow[t]{3}{*}{ New quinolones } & Enoxacin & $10 \mu \mathrm{g}$ & 0 & 0 & 100 & $\mathrm{R}$ & $\mathrm{R}$ \\
\hline & Ofloxacin & $5 \mu \mathrm{g}$ & 0 & 68 & 32 & MS & MS \\
\hline & Pefloxacin & $5 \mu \mathrm{g}$ & 0 & 0 & 100 & $\mathrm{R}$ & $\mathrm{R}$ \\
\hline $\begin{array}{l}\text { Sulphonamides + } \\
\text { trimethoprim }\end{array}$ & $\begin{array}{l}\text { Sulphamethoxazole }+ \\
\text { trimethoprim }\end{array}$ & $25 \mu \mathrm{g}$ & 0 & 0 & 100 & $\mathrm{R}$ & $\mathrm{R}$ \\
\hline
\end{tabular}

a Susceptibility expressed as S (Susceptible), MS (Moderately Susceptible) or R (Resistant) [14].

* International Units. 
was susceptible to all the inhibitors of protein synthesis tested with the exception of neomycin and lincomycin; $L$. GG was moderately susceptible to clarithromycin, resistant to gentamicin, neomycin and lincomycin and susceptible to all the other aminoglycosides tested.

\subsection{Susceptibility to inhibitors of nucleic acid synthesis}

All strains were sensitive to rifampicin and resistant to enoxacin, pefloxacin and sulphamethoxazole-trimethoprim; $68 \%$ and $32 \%$ of the strains were moderately susceptible or resistant to ofloxacin, respectively.

L. rhamnosus DSM $20021^{\mathrm{T}}$ and $L$. GG were susceptible to rifampicin, moderately sensible to ofloxacin and resistant to enoxacin, pefloxacin and sulphamethoxazole-trimethoprim.

\subsection{Biodiversity of the isolates}

The results of RAPD-PCR and antibiotic-susceptibility analyses of the 65 assayed strains are reported in the form of dendrograms in Figure 1.

The strains tested were ascribable to L. rhamnosus subsp. at a $64 \%$ similarity level at least (Fig. 1a). The effective identity of the isolates as L. rhamnosus was confirmed by species-specific PCR (Fig. 2). The low level of similarity with the type strain L. rhamnosus DSM 20021 highlighted a strong intra-specific biodiversity between the strains assayed.

Only in some cases it was possible to point out a high similarity of strains belonging to the same dairy plant, while in other cases a high similarity was ascertained between strains deriving from different dairy plants. This datum was also evidenced in Figure 1b.

Comparing similarity levels obtained from the dendrograms illustrated in Figure $1 \mathrm{a}$ and $1 \mathrm{~b}$, it was possible to observe the presence in the same cluster in both dendrograms only of certain strains.

\section{DISCUSSION}

The study of antibiotic resistance in strains of L. rhamnosus isolated from Parmigiano Reggiano gave different results.

The lactobacilli tested were susceptible to 18 antibiotics and manifested resistance to six types of antibiotics, while different percentages of strains were resistant to seventeen other antibiotics.

Among the inhibitors of cell wall synthesis, the L. rhamnosus strains assayed in the present work were susceptible to most penicillins, $\beta$-lactamase inhibitors and, among single antibiotics, to imipenem.

In particular, ampicillin, cloxacillin, mezlocillin, piperacillin and ticarcillin were strong inhibitors, while a low inhibition was ascertained with the use of amoxicillin and oxacillin.

Charteris et al. [14] tested the susceptibility of different Lactobacillus species to 44 antibiotics and, among the inhibitors of cell wall synthesis, the assayed strains exhibited susceptibility to almost all penicillins, cephalosporins and $\beta$-lactamase inhibitors.

In the study of Temmerman et al. [40], L. rhamnosus strains isolated from probiotic products were resistant to penicillin G.

Holley and Blaszyk [22] reported that penicillin $G$ is more active than either amoxicillin or ampicillin against lactobacilli cultures, but our study showed a greater inhibitory action of ampicillin on L. rhamnosus strains from Parmigiano Reggiano cheese.

Beta-lactamase inhibitors, which are considered to be active on Gram-positive and Gram-negative bacteria, evidenced a great susceptibility of the strains isolated from Parmigiano Reggiano cheese, while a different response to cephalosporins was observed. In fact, among this group of antibiotics, cefazolin, cefoperazone and cefuroxime showed inhibitory effects, while a high resistance was observed to cefadroxil, cephalexin, cefixime and ceftriaxone. The response to ceftazidime was strain-specific: $43 \%$ were moderately sensible, $24 \%$ were 
$a$

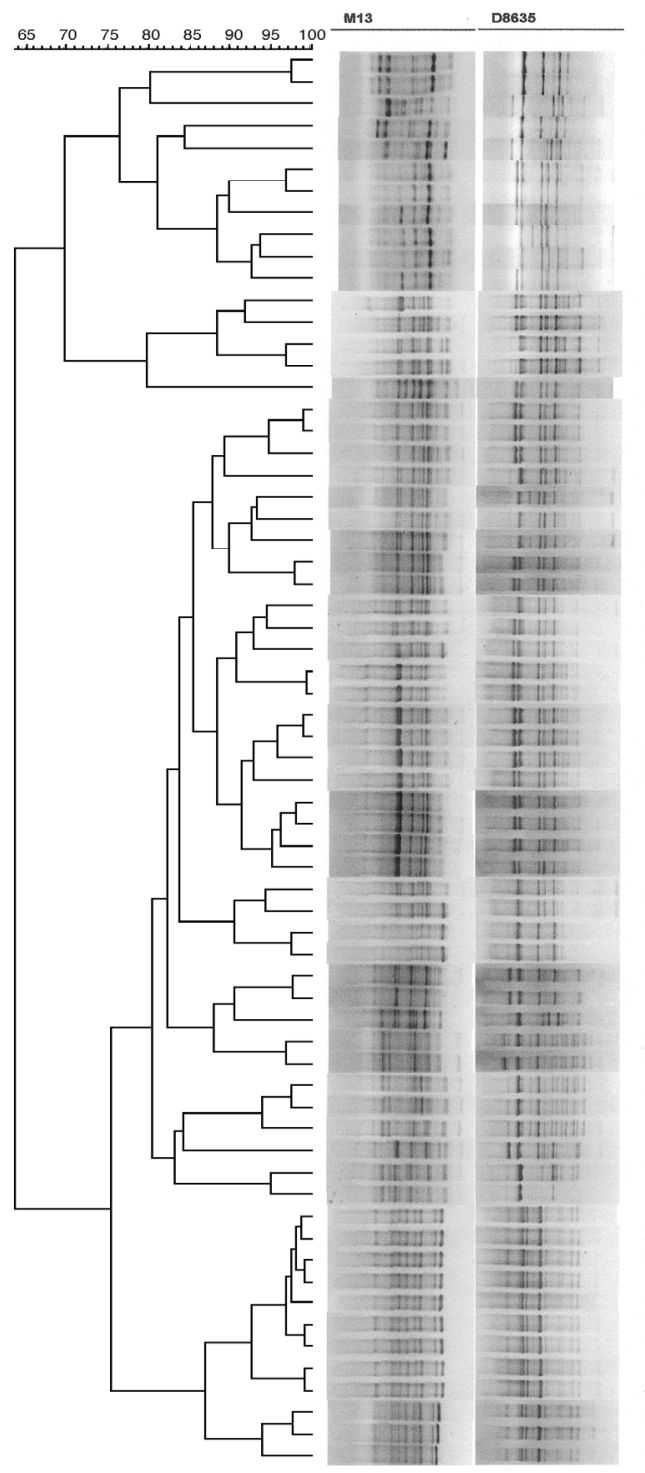

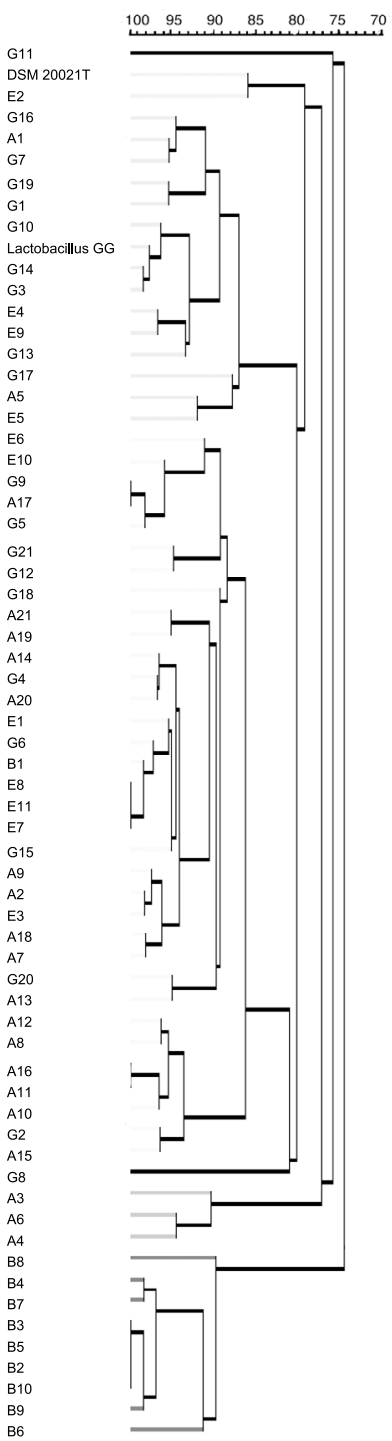

Figure 1. Cluster analysis obtained by RAPD-PCR performed with primers M13 and D8635 (a) and by antibiotic-resistance profiles (b) of 63 Lactobacillus rhamnosus strains isolated from Parmigiano Reggiano cheese, of the commercial strain $L$. GG and of the type strain L. rhamnosus DSM 20021. 


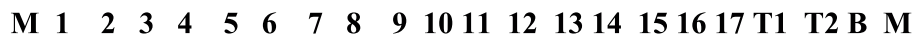

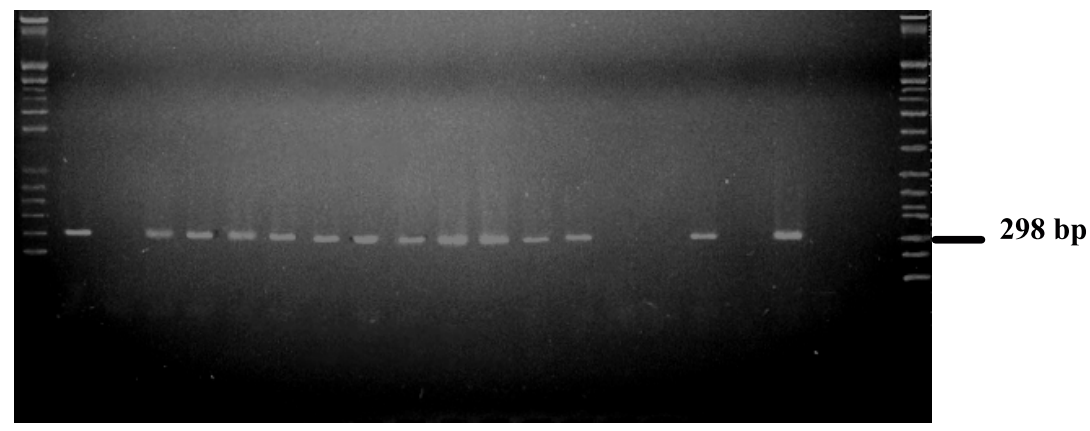

\section{$\begin{array}{lllllllllllll}\text { M } & 18 & 19 & 20 & 21 & 22 & 23 & 24 & 25 & \text { T1 } & \text { T3 } & \text { B } & \text { M }\end{array}$}

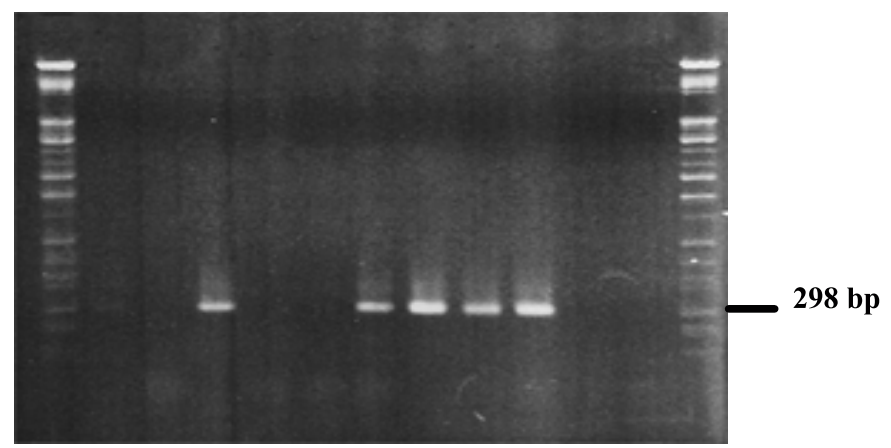

Figure 2. Lactobacillus rhamnosus species-specific PCR performed with primers rhamn and Y2 [45] on 17 lactobacilli isolated from Parmigiano Reggiano cheese. Lane M: molecular weight marker; B: blank; T1: Lactobacillus rhamnosus type strain DSM 20021; T2: Lactobacillus paracasei subsp. paracasei type strain DSM 5622; T3: Lactobacillus casei type strain DSM 20011; lanes 1, 3-13, 16, 20, 23-25: lactobacilli isolated from cheese, identified as Lactobacillus rhamnosus with RAPD-PCR analysis and belonging to different clusters; lanes 2, 14, 15, 17-19, 21, 22: Lactobacillus paracase $i$ subsp. paracase $i$ from the DISTAAM (University of Molise) collection and isolated from food.

sensible and $33 \%$ were resistant. A similar variability in the susceptibility of lactobacilli to cephalosporins was also evidenced by other authors $[12,14]$.

As previously described among single inhibitors of cell wall synthesis, imipenem revealed inhibitory effects on all the strains. This datum is in contrast to that shown in the study performed on Lactobacillus species from the Chr. Hansen Culture Collection by Danielsen and Wind [17].

Among other single antibiotic inhibitors of cell wall synthesis, vancomycin revealed a resistance of all the assayed strains, while bacitracin and teicoplanin revealed a high percentage of resistance. The inhibitory effects of these antibiotics on Lactobacillus species were previously reported by other authors [8, 12, 14].

Vancomycin and teicoplanin are both active against most Gram-positive bacteria. A number of Lactobacillus species, however, are intrinsically resistant to glycopeptides $[18,23,39]$. Differential susceptibility to vancomycin may be helpful in speciation of lactobacilli. The finding that all the strains 
tested in the present study were resistant to this antibiotic is in accordance with the results of Hamilton-Miller and Shah [20] and with previous studies, which have shown that the vancomycin resistance in lactobacilli is intrinsic and chromosomally encoded [11].

Among the inhibitors of protein synthesis, tetracyclines (doxicycline, minocyclin and tetracycline) showed a great inhibitory action on the assayed lactobacilli. These results are in agreement with those reported by Charteris et al. [14] and by Baumgartner et al. [8]. However, in some cases a resistance to tetracycline was observed in L. plantarum strains [12].

Among aminoglycosides, gentamicin is especially indicated for the treatment of infections by Gram-negatives, and its inhibition potency showed an insignificant inhibition on the tested strains. The same result was evidenced with the use of neomycin, which, although very toxic, is regarded as an antibiotic for general purposes. For this reason, it is exclusively used for topical purposes or combined with bacitracin to fight against dysentery. Charteris et al. [14] reported the resistance of lactobacilli to aminoglycosides (amikacin, gentamicin, kanamicin, netilmicin and streptomycin) with variability in susceptibility only to netilmicin, whereas Cebeci and Gürakan [12] reported a high variability in susceptibility to gentamicin in L. plantarum strains. On the other hand, Baumgartner et al. [8] showed a high susceptibility of $L$. rhamnosus strains to gentamycin and neomycin.

Macrolides showed a strong inhibitory action on L. rhamnosus strains isolated from Parmigiano Reggiano cheese, while Baumgartner et al. [8] evidenced the susceptibility of both L. plantarum and L. rhamnosus strains to erythromicin.

Among lincosamides, clindamycin inhibited all the assayed strains, while the majority of them were resistant to lincomycin (86\%). Lincomycin and clindamycin are especially active against Gram-negative bacteria. Moreover, the inhibitory action of clindamycin on lactobacilli has been widely shown by many authors $[8,12,22]$, even if Charteris et al. [14] evidenced a resistance of some L. casei or L. plantarum strains to this antibiotic.

Chloramphenicol exerted a strong inhibitory action on all the assayed strains. Sensibility of Lactobacillus species to chloramphenicol was ascertained by many authors [5, 8, 14, 27], but in some cases a resistance to this antibiotic was observed $[13,29,40]$.

Among the inhibitors of nucleic acid synthesis, a strong resistance of L. rhamnosus strains was observed against sulphonamides plus trimethoprim. The resistance to sulphamethoxazole found is not surprising since this antibiotic acts positively toward Gram-positive and -negative cocci and Gram-negative bacilli. This was in agreement with that shown by other authors $[14$, 27].

Among new quinolones, enoxacin and pefloxacin inhibited all the assayed strains; no susceptibility was ascertained to ofloxacin, but $68 \%$ of the strains were moderately susceptible to this antibiotic. Charteris et al. [14] reported the resistance of potentially probiotic lactobacilli to all quinolones, except ciprofloxacin.

The susceptibility of the assayed strains to rifampicin was previously described by Charteris et al. [14], but other authors have described a strong resistance to this antibiotic $[8,12]$.

The results obtained in the present study with regard to the susceptibility of $L$. rhamnosus strains isolated from Parmigiano Reggiano cheese to different antibiotics partially agree with those obtained by other authors, as previously evidenced. In some cases, the response to the different classes of antibiotics seems to depend on the species but, inside the species, it was possible to observe a strain-specific response for the antibiotic resistance.

RAPD-PCR and antibiotic-susceptibility analyses highlighted a strong intra-specific biodiversity between the strains tested. 
The findings of strains isolated from the same sample of Parmigiano Reggiano cheese with very dissimilar profiles of RAPD-PCR bands testify the importance of the use of natural whey starter in this type of cheese as a source of a strong biodiversity [16]. On the other hand, the similarity in the profiles of RAPD-PCR bands for strains isolated from different samples of Parmigiano Reggiano cheese evidenced the influence of the raw milk, obtained from pastures of the same, defined geographic area, used in the manufacture of this kind of cheese.

The observation of RAPD-PCR (Fig. 1a) and antibiotic susceptibility profiles (Fig. 1b) gave way to some considerations.

In fact, only some strains, e.g., B2, B4, $\mathrm{B} 5, \mathrm{~B} 6, \mathrm{~B} 7, \mathrm{~B} 8, \mathrm{~B} 9$ and $\mathrm{B} 10$, belonged to the same cluster in both dendrograms. This result highlights the biodiversity among the strains isolated and allows the supposition that only in a few cases the presence of sister colonies could occur.

In fact, strains with a great similarity resulting from RAPD-PCR analysis (see strains B2 and A20 in Fig. 1a) generally showed very different antibiotic-susceptibility profiles. This could be imputable to the fact that RAPD-PCR technique is based on the random amplification of genomic DNA regions by specific primers, and the antibiotic-susceptibility/resistance factor is chromosomally coded [41]. However, it can be assumed that when lactic acid bacteria live in association with other microbes, the resulting contact with other bacteria is a precondition for horizontal gene transfer with the aid of conjugative transposons and plasmids [41].

Finally, Çataloluk and Gogebakan [11] pointed out that the presence of the resistance genes in the majority of the lactobacilli of intestinal origin suggests that transfer of such genes from an unknown origin during the passage from the intestinal tract is more likely.

This possibility worried microbiologists for a long time and today there is a strong tendency to avoid the distribution of bacteria with mobilisable antibiotic resistances.

The fact that L. rhamnosus strains isolated from Parmigiano Reggiano cheese gave different responses to the assayed antibiotics demonstrates the importance of individually testing the strains for their use as probiotics.

Moreover, the finding of resistance of L. rhamnosus GG to eighteen antibiotics (amoxicillin, oxacillin, cefadroxil, cephalexin, cefixime, ceftazidime, ceftriaxone, cefuroxime, ticarcillin-clavulanic acid, bacitracin, teicoplanin, vancomycin, gentamicin, neomycin, lincomycin, enoxacin, pefloxacin and sulphamethoxazole) suggests that it has become more and more imperative to regularly test the behaviour of all strains to be proposed as probiotics.

This is in agreement with the results obtained by Vanderhoof et al. [43] and Klein et al. [28] and allows the conclusion that the antibiotic resistance ascertained in L. rhamnosus $\mathrm{GG}$ is natural.

On the other hand, antibiotic resistance can be easily transferred via plasmids which, as stated by Tynkkynen et al. [42], are absent in $L$. GG.

This evidence, however, does not consent to conclude that all strains are plasmidfree and further investigations could point out the presence of plasmids in other strains ascribable to L. rhamnosus.

\section{REFERENCES}

[1] Aguirre M., Collins M.D., Lactic acid bacteria and human clinical infection, J. Appl. Bacteriol. 75 (1993) 95-107.

[2] Akopyanz N., Bukanov N.O., Westblom T.U., Kresovich S., Berg D.E., DNA diversity among clinical isolates of Helicobacter pylori detected by PCR-based RAPD fingerprinting, Nucl. Acids Res. 20 (1992) $5137-$ 5142.

[3] Alander M., Korpela R., Saxelin M., Vilpponen-Salmela T., Mattila Sandholm T., von Wright A., Recovery of Lactobacillus rhamnosus GG from human colonic 
biopsies, Lett. Appl. Microbiol. 24 (1997) 361-364.

[4] Andrighetto C., Zampese L., Lombardi A., RAPD-PCR characterization of lactobacilli isolated from artisanal meat plants and traditional fermented sausages of Veneto region (Italy), Lett. Appl. Microbiol. 32 (2001) 1-5.

[5] Arici M., Bilgin B., Sagdic O., Ozdemir C., Some characteristics of Lactobacillus isolates from infant faeces, Food Microbiol. 21 (2004) 19-24.

[6] Avlami A., Kordossis T., Vrizidis N., Sipsas N.V., Lactobacillus rhamnosus endocarditis complicating colonoscopy, J. Infect. 42 (2001) 283-285.

[7] Bauer A.W., Kirby W.M.M., Sherris J.C., Turk M., Antibiotic susceptibility testing by a standardized single disk method, Amer. J. Clin. Pathol. 45 (1966) 493-496.

[8] Baumgartner A., Kueffer M., Simmen A., Grand M., Relatedness of Lactobacillus rhamnosus strains isolated from clinical specimens and such from food-stuffs, humans and technology, Lebensm. Wiss. u. Technol. 31 (1998) 489-494.

[9] Berild D., Smaabrekke L., Halvorsen D.S., Lelek M., Stahlsberg E.M., Ringertz S.H., Clostridium difficile infections related to antibiotic use and infection control facilities in two university hospitals, J. Hosp. Infect. 54 (2003) 202-206.

[10] Borriello S.P., Hammes W.P., Holzapfel W., Marteau P., Schrezenmeir J., Vaara M., Valtonen V., Safety of probiotics that contain lactobacilli or bifidobacteria, Clin. Infect. Dis. 36 (2003) 775-780.

[11] Çataloluk O., Gogebakan B., Presence of drug resistance in intestinal lactobacilli of dairy and human origin in Turkey, FEMS Microbiol. Lett. 236 (2004) 7-12.

[12] Cebeci A., Gürakan C., Properties of potential probiotic Lactobacillus plantarum strains, Food Microbiol. 20 (2003) 511-518.

[13] Chang Y.H., Kim J.K., Kim H.J., Kim W.Y., Kim Y.B., Park Y.H., Selection of potential probiotic Lactobacillus strain and subsequent in vivo studies, Antonie van Leeuwenhoek 80 (2001) 193-199.

[14] Charteris W.P., Kelly P.M., Morelli L., Collins J.K., Antibiotic susceptibility of potentially probiotic Lactobacillus species, J. Food Prot. 61 (1998) 1636-1643.

[15] Coppola R., Nanni M., Iorizzo M., Sorrentino A., Sorrentino E., Grazia L., Survey of lactic acid bacteria involved in the ripening of Parmigiano Reggiano cheese, J. Dairy Res. 64 (1997) 305-310.
[16] Coppola R., Nanni M., Iorizzo M., Sorrentino A., Sorrentino E., Chiavari C., Grazia L., Microbiological characteristics of Parmigiano Reggiano cheese during the cheesemaking and the first months of the ripening, Lait 80 (2000) 479-480.

[17] Danielsen M., Wind A., Susceptibility of Lactobacillus spp. to antimicrobial agents, Int. J. Food Microbiol. 82 (2003) 1-11.

[18] Felten A., Barreau C., Bizet C., Lagrange P.H., Philippon A., Lactobacillus species identification, $\mathrm{H}_{2} \mathrm{O}_{2}$ production, and antibiotic resistance and correlation with human clinical status, J. Clin. Microbiol. 37 (1999) 729-733.

[19] Goldin B.R., Gorbach S.L., Saxelin M. Barakat S., Gualtieri L., Salminen S., Survival of Lactobacillus strain GG in the human gastrintestinal tract, Dig. Dis. Sci. 37 (1992) 121-128.

[20] Hamilton-Miller J.M., Shah S., Vancomycin susceptibility as an aid to the identification of lactobacilli, Lett. Appl. Microbiol. 27 (1998) 121

[21] Hammes W.P., Vogel R F., The genus Lactobacillus, in: Wood B.J.B., Holzaphel W.H (Eds.), The genera of lactic acid bacteria, Blackie, Academic \& Professional, Glasgow, UK, 1995, pp. 19-54.

[22] Holley R.A., Blaszyk M., Antibiotic challenge of meat starter cultures and effects upon fermentations, Food Res. Int. 30 (1998) 513-522.

[23] Holliman R.E., Bone G.P., Vancomycin resistance of clinical isolates of lactobacilli, J. Infect. 16 (1988) 279-283.

[24] Huey B., Hall J., Hypervariable DNA fingerprinting in Escherichia coli. Minisatellite probe from bacteriophage M13, J. Bacteriol. 171 (1989) 2528-2532.

[25] Iwana H., Masuda H., Fujisawa T., Suzuki H., Mitsuoka T., Isolation and identification of Bifidobacterium spp. in commercial yoghurt sold in Europe, Bifidobact. Microflora 12 (1993) 39-45.

[26] Kaltenbach G., Heitz D., Antibiotic-associated diarrhea in the elderly, Rev. Med. Interne 25 (2004) 46-53.

[27] Katla A.K., Kruse H., Johnsen G., Herikstad H., Antimicrobial susceptibility of starter culture bacteria used in Norwegian dairy products, Int. J. Food Microbiol. 67 (2001) 147-152.

[28] Klein G., Hallmann C., Casas I.A., Abad J., Louwers J., Reuter G., Exclusion of vanA, vanB and vanC type glycopeptide resistance in strains of Lactobacillus reuteri and Lactobacillus rhamnosus used as probiotics by polymerase chain reaction and hybridization 
methods, J. Appl. Microbiol. 89 (2000) 815824.

[29] Lin C.F., Fung Z.F., Wu C.L., Chung T.C., Molecular characterization of a plasmidborne (pTC82) chloramphenicol resistance determinant (cat-TC) from Lactobacillus reuteri G4, Plasmid 36 (1996) 116-124.

[30] Majamaa H., Isolauri E., Probiotics: a novel approach in the management of food allergy, J. Allerg. Clin. Immunol. 99 (1997) 179186.

[31] Millar M.R., Bacon C., Smith S.L., Walker V., Hall M.A., Enteral feeding of premature infants with Lactobacillus GG, Arch. Dis. Child. 69 (1993) 483-487.

[32] Nanni M., Coppola R., Iorizzo M., Sorrentino A., Sorrentino E., Grazia L., La microflora lattica nella maturazione del formaggio Parmigiano Reggiano, Sci. Tec. Latt.-Casearia 48 (1997) 211-216.

[33] NCCLS, SC21-L, Susceptibility Testing, National Committee for Clinical Laboratory Standards, Villanova, PA, 2004.

[34] Nigatu A., Evaluation of numerical analyses of RAPD and API $50 \mathrm{CH}$ patterns to differentiate Lactobacillus plantarum, Lact. fermentum, Lact. rhamnosus, Lact. sake, Lact. parabuchneri, Lact. gallinarum, Lact. casei, Weissella minor and relted taxa isolated from kocho and tef, J. Appl. Microbiol. 89 (2000) 969-978.

[35] Salminen S., Isolauri E., Salminen E., Clinical uses of probiotics for stabilizing the gut mucosal barrier: successful strains and future challenges, Antonie Van Leeuwenhoek 70 (1996) 347-358.

[36] Salminen M.S., Rautelin H., Tynkkynen S., Poussa T., Saxelin M., Valtonen V., Jarvinen A., Lactobacillus bacteremia, clinical significance, and patient outcome, with special focus on probiotic L. rhamnosus GG, Clin. Infect. Dis. 38 (2004) 62-69.

[37] Saxelin M., Ahokas M., Salminen M., Dose response on the faecal colonisation of Lacto- bacillus strain GG admistered in two different formulations, Microb. Ecol. Health Dis. 6 (1993) 119-122.

[38] Shu Q., Shou J.S., Rutherfurd K.J., Birtles M.J., Prasad J., Gopal P.K., Gill H.S., Probiotic lactic acid bacteria (Lactobacillus acidophilus HN017, Lactobacillus rhamnosus HN001 and Bifidobacterium lactis HN019) have no adverse effects on the health of mice, Int. Dairy J. 9 (1999) 831-836.

[39] Swenson J.M., Facklam R.R., Thornsberry C., Antimicrobial susceptibility of vancomycin-resistant Leuconostoc, Pediococcus, and Lactobacillus species, Antimicrob. Agents Chemother. 34 (1990) 543-547.

[40] Temmerman R., Pot B., Huys G., Swings J., Identification and antibiotic susceptibility of bacterial isolates from probiotic products, Int. J. Food Microbiol. 81 (2002) 1-10.

[41] Teuber M., Meile L., Schwarz F., Acquired antibiotic resistance in lactic acid bacteria from food, Antonie van Leeuwenhoek 76 (1999) 115-137.

[42] Tynkkynen S., Singh K.V., Varmanen P., Vancomycin resistance factor of Lactobacillus rhamnosus GG in relation to enterococcal vancomycin resistance (van) genes, Int. J. Food Microbiol. 41 (1998) 195-204.

[43] Vanderhoof J.A., Whitney D.B., Antonson D.L., Hanner T.L., Lupo J.V., Young R.J., Lactobacillus GG in the prevention of antibiotic-associated diarrhea in children, J. Pediatr. 135 (1999) 564-568.

[44] Vauterin L., Vauterin P., Computer-aided objective comparison of electrophoresis patterns for grouping and identification of microorganisms, Eur. Microbiol. 1 (1992) 37-41.

[45] Ward L.J.H., Timmins M.J., Differentiation of Lactobacillus casei, Lactobacillus paracasei and Lactobacillus rhamnosus by polymerase chain reaction, Lett. Appl. Microbiol. 29 (1999) 90-92. 